\title{
Relative proportions of polycyclic aromatic hydrocarbons differ between accumulation bioassays and chemical methods to predict bioavailability
}

Article

Accepted Version

Gomez-Eyles, J. L., Collins, C. D. and Hodson, M. E. (2010) Relative proportions of polycyclic aromatic hydrocarbons differ between accumulation bioassays and chemical methods to predict bioavailability. Environmental Pollution, 158 (1). pp. 278-284. ISSN 0269-7491 doi:

https://doi.org/10.1016/j.envpol.2009.07.012 Available at https://centaur.reading.ac.uk/1655/

It is advisable to refer to the publisher's version if you intend to cite from the work. See Guidance on citing.

To link to this article DOI: http://dx.doi.org/10.1016/j.envpol.2009.07.012

Publisher: Elsevier

All outputs in CentAUR are protected by Intellectual Property Rights law, including copyright law. Copyright and IPR is retained by the creators or other copyright holders. Terms and conditions for use of this material are defined in the End User Agreement. 


\section{www.reading.ac.uk/centaur}

\section{CentAUR}

Central Archive at the University of Reading

Reading's research outputs online 
1 Relative proportions of polycyclic aromatic hydrocarbons differ between accumulation bioassays and chemical methods to predict

\section{bioavailability}

4 Jose L. Gomez-Eyles ${ }^{\mathrm{a}, *}$, Chris D. Collins ${ }^{\mathrm{a}}$ and Mark E. Hodson ${ }^{\mathrm{a}}$

5

$6 \quad{ }^{a}$ University of Reading, School of Human and Environmental Sciences, Department

7 of Soil Science, Reading, RG6 6DW, Berkshire, United Kingdom.

8

9

10

11

12

13

14

15

16

17

18

19

20

21

22

23

24 *Corresponding author. Tel: +44 1183787903 Fax: +44 1183786666

25 Email address: j.l.gomezeyles@ reading.ac.uk (J.L. Gomez-Eyles) 
28 Chemical methods to predict the bioavailable fraction of organic contaminants are

29 usually validated in the literature by comparison with established bioassays. A soil

30 spiked with polycyclic aromatic hydrocarbons (PAHs) was aged over six months and

31 subjected to butanol, cyclodextrin and tenax extractions as well as an exhaustive extraction to determine total PAH concentrations at several timepoints. Earthworm $(E$. fetida) and rye grass root (L. multiflorum) accumulation bioassays were conducted in parallel. Butanol extractions gave the best relationship with earthworm accumulation $\left(r^{2} \leq 0.54, p \leq 0.01\right)$; while cyclodextrin, butanol and acetone-hexane extractions all gave good predictions of accumulation in rye grass roots $\left(\mathrm{r}^{2} \leq 0.86, \mathrm{p} \leq 0.01\right)$. However, the profile of the PAHs extracted by the different chemical methods was significantly different $(\mathrm{p}<0.01)$ to that accumulated in the organisms. Biota accumulated a higher proportion of the heavier 4-ringed PAHs. It is concluded that bioaccumulation is a complex process that cannot be predicted by measuring the bioavailable fraction

41 alone.

\section{Keywords}

bioavailability, polycyclic aromatic hydrocarbons, earthworms, plants, accumulation

\section{Capsule}

47 The ability of chemical methods to predict PAH accumulation in E. fetida and $L$. multiflorum was hindered by the varied metabolic fate of the different PAHs within

49 the organisms 


\section{Introduction}

53 As organic compounds age in soil they become less available for uptake by 54 organisms, and are thus less likely to have toxic effects or be degraded by soil microorganisms (Alexander, 2000). The biological effects of a contaminant are therefore not related to its total concentration, but to the bioavailable fraction. This is the fraction of the contaminant that is biologically available for uptake.

Regulators and the public are used to a system where total concentrations are considered as well founded and definitive values, although there are now new approaches for ecological risk assessment where bioavailability data, obtained from the results of bioassays, have a more important role (Harmsen, 2007). Bioassays only respond to the bioavailable fraction of contaminants and have the advantage of being able to consider site-specific effects of mixtures of contaminants and their metabolites (Jensen and Mesman, 2007). Although they are the most established method of quantifying bioavailability, their application may be time consuming and laborious, so a large number of theoretically more time and cost-efficient chemical methods for predicting bioavailability have been published in the scientific literature (Kelsey et al., 1997; Reid et al., 2000; Ten Hulscher et al., 2003).

The most frequent approach to evaluate chemical methods for the prediction of polycyclic aromatic hydrocarbon (PAH) bioavailability is by comparing how they approximate or correlate with the amount of organic compound accumulated by soil biota such as earthworms and to a lesser extent plants, or the amount degraded by microbes (Kelsey et al., 1997; Tang and Alexander, 1999; Reid et al., 2000; Liste and 
Alexander, 2002; Tang et al., 2002; Ten Hulscher et al., 2003; Hickman and Reid, 2005; Bergknut et al., 2007). When correlating chemical predictors of bioavailability to bioassays it is important to consider that the bioavailability being measured is specific to the organism used in that particular bioassay, and also to be aware that the determination of earthworm or plant accumulation does not necessarily measure contaminant bioavailability, but rather measures an interaction end-point between the organism and the compound (Hickman and Reid, 2005).

Earthworms are appropriate model organisms for bioavailability as they live in intimate contact with the soil, have a thin and permeable cuticle and consume large volumes of soil (Jager et al., 2005). They have been used in many studies as reference systems for organic compound bioavailability due to their importance in the terrestrial food chain, their potential to accumulate contaminants and ease of handling in the laboratory (Kelsey et al., 1997; Tang and Alexander, 1999; Liste and Alexander, 2002; Tang et al., 2002; Ten Hulscher et al., 2003; Van der Wal et al., 2004a;

Hickman and Reid, 2005; Bergknut et al., 2007). Considerably less work has been carried out using plant accumulation as a reference system (Tang and Alexander, 1999; Tao et al., 2006a).

This study aims to compare how a range of chemical methods (namely extractions using butanol, cyclodextrin or tenax), frequently tested in isolation, predict PAH bioavailability using two different accumulation bioassays (earthworms and plants) as reference systems. It is important to consider different reference systems as bioavailability has been shown to vary between different organisms (Kelsey et al., 1997; Stroo et al., 2000). 


\subsection{Soil spiking and ageing}

105

106 A 2 mm sieved Kettering Loam soil (Broughton Loam, Kettering, UK) (Table 1) was spiked using a single-step spiking/re-hydration procedure (Reid et al., 1998) with a stock solution of naphthalene and acenapthene (2-ringed PAHs), fluorene and phenanthrene (3-ringed PAHs) and fluoranthene and pyrene (4-ringed PAHs) (Sigma

110 Chemicals, Poole, UK) in acetone, to final concentrations of approximately 90 and

$111450 \mathrm{mg} \mathrm{kg}^{-1}$ total PAH with equal concentrations of each PAH. After addition of the

112 stock solution, the soil was left uncovered in a fume hood for $24 \mathrm{~h}$ to ensure all the

113 solvent had evaporated. After checking for removal of the solvent by olfactory

114 detection and checking for residual wetting in the soil, the spiked soil was re-wetted to

$11560 \%$ of its water holding capacity, transferred to 10 loosely sealed amber glass jars (5

116 for each concentration) and aged for 6 months at $20^{\circ} \mathrm{C}$. After $0,1,2,3$ and 6 months,

1172 jars (1 of each concentration) were emptied for use in the different chemical

118 extractions and bioassays. A non-spiked $2 \mathrm{~mm}$ sieved Kettering Loam soil was used

119 as a control in all soil extractions and bioassays.

$120 \quad 2.2$ Soil extractions

122 To determine the total amount of PAHs in the soil, five replicate $2 \mathrm{~g}$ portions of soil

123 were agitated in $10 \mathrm{ml}$ of 1:1 by volume acetone/hexane mixture for 1.5 hours on an

124 end over end shaker. After extraction the samples were left to settle for $30 \mathrm{~min}$, and

125 then $2 \mathrm{ml}$ of solution were placed in a test tube containing $0.1 \mathrm{~g}$ of dry sodium 
sulphate before transferring to gas chromatography (GC) vials for analysis. This method was adapted from a mechanical shaking method previously reported to give better recoveries than a Soxhlet extraction (Song et al., 2002). This adapted method was also found to give better recoveries than a soxhlet extraction in a preliminary

130 study. Native PAH concentrations in the control soils were below the method

131 detection limit $\left(0.5 \mathrm{mg} \mathrm{kg}^{-1}\right)$.

132

133 Three different kinds of butanol extraction were carried out; a vortex extraction where

$13410 \mathrm{~g}$ of soil were mixed in $10 \mathrm{ml}$ of butanol solvent and agitated for $50 \mathrm{~s}$ (Swindell 135 and Reid, 2006) or $120 \mathrm{~s}$ (Liste and Alexander, 2002) and then left to settle for 30 136 minutes, and a shake (Reid et al., 2004) where $10 \mathrm{~g}$ of soil were mixed with $15 \mathrm{ml}$ of 137 butanol and placed on an end over end shaker for 12 hours and then left to settle for 13830 minutes. All butanol extractions were replicated 5 times and analysed using GC-

139 FID. The method detection limits were $0.10 \mathrm{mg} \mathrm{kg}^{-1}$ and $0.15 \mathrm{mg} \mathrm{kg}^{-1}$ for the butanol 140 mix and shake respectively.

142 Cyclodextrin extractions (Stokes et al., 2005) were carried out in triplicate by mixing $1431.5 \mathrm{~g}$ of soil with a $25 \mathrm{ml}$ solution of 60-mM HPCD (Sigma Aldrich, Poole, UK) in 144 deionised water and agitating the mixture for 20 hours using an orbital shaker (Orbital 145 Shaker SO1, Bibby Sterilin Ltd, Stone, Staffordshire, UK) at $200 \mathrm{rpm}$. The mixture 146 was then centrifuged at $2500 \mathrm{rpm}$ using a Mistral 3000i centrifuge (MSE Sanyo-

147 Gallenkamp, Leicester, UK) for 30 minutes and the supernatant discarded. The 148 resulting soil pellet was shaken with $25 \mathrm{ml}$ of deionised water for $10 \mathrm{~s}$, centrifuged 149 again and the supernatant was again discarded to remove any remaining HPCD 150 solution. The soil pellet was then exhaustively extracted using the acetone/hexane 
151 mechanical shaking extraction described above. GC analysis of this exhaustive

152 extraction measured the PAHs remaining in the soil after HPCD extraction. The

153 method detection limit was $0.67 \mathrm{mg} \mathrm{kg}^{-1}$.

155 Tenax extractions (Ten Hulscher et al., 2003) were also carried out in triplicate by

156 mixing $1.4 \mathrm{~g}$ of soil and $1 \mathrm{~g}$ of Tenax $\mathrm{TA}^{\circledR}$ beads $(60 / 80 \mathrm{mesh}, 177-250 \mu \mathrm{m}$, Sigma

157 Aldrich) in $70 \mathrm{ml}$ of deionised water and placing them on an end over end shaker for 6

158 hours. The beads were separated from the soil, rinsed with distilled water to remove

159 soil particulates and solvent extracted by ultrasonicating them in $10 \mathrm{ml}$ of hexane for

1601 hour. The solvent samples were then analysed by GC-FID. The method detection

161 limit was $0.71 \mathrm{mg} \mathrm{kg}^{-1}$.

162

163 Chemical extractions were carried out in months $0,1,2,3$ and 6 except the Tenax

164 extractions that were only carried out at months 0,2 and 6.

165

$166 \quad 2.3$ Earthworm bioassays

167

168 Earthworms (Eisenia fetida) were obtained from Blades Biological (Cowden, UK).

169 Only adult worms with a clitellum were used in the bioassays. Five worms were

170 exposed to $300 \mathrm{~g}$ of the spiked soil (after $0,1,2,3$ and 6 months of ageing) at $20^{\circ} \mathrm{C}$ for

17114 days. After exposure, the worms were rinsed with water and kept on wet filter

172 paper for $24 \mathrm{~h}$ for depuration of their guts. They were then weighed and frozen at -20

$173{ }^{\circ} \mathrm{C}$ before being ground with 7 times their weight of dry sodium sulphate using a

174 pestle and mortar. Tissues were then extracted following a saponiphication method to

175 remove fat from the earthworms (Contreras-Ramos et al., 2008). This consisted of 
adding $10 \mathrm{ml}$ of $0.5 \mathrm{M} \mathrm{KOH}$ and $10 \mathrm{ml}$ of a $1: 1$ acetone/hexane solvent mixture to the ground earthworm and ultrasonicating the mixture at $45^{\circ} \mathrm{C}$ for 1 hour. The solvent layer was then cleaned on a deactivated silica column, pre-eluted with $5 \mathrm{ml}$ of 1:1 acetone/hexane. The sample was then eluted with a further $5 \mathrm{ml}$ of 1:1 acetone/hexane

180 before being concentrated down to $1 \mathrm{ml}$ by nitrogen blowdown prior to analysis by

181 GC/MS.

\subsection{Plant bioassays}

Rye grass (Lolium multiflorum) was grown for 4 weeks in the soil (after 0,1,2 and 3 months of ageing) in a temperature controlled greenhouse. After 4 weeks the plants were harvested and the roots separated from the soil. Root samples were rinsed with deionised water, wiped with tissue paper and freeze-dried (Super Modulyo 12K Freeze Dryer, Edwards, Crawley, West Sussex, UK) overnight. The dried roots were then ground, homogenized and weighed prior to ultrasonication for 2 hours in $10 \mathrm{ml}$

191 of dichloromethane. The extracts were then concentrated down to $1 \mathrm{ml}$ by nitrogen blowdown and passed through $0.45 \mu \mathrm{m}$ filters obtained from Chromacoal Ltd

193 (Welwyn Garden City, UK) before being transferred to GC vials. Solutions were 194 analysed by GC/MS.

\subsection{GC-FID analysis}

197 Soil extraction samples were all analysed using an Agilent 6890N Network GC

198 system equipped with a HP5 capillary column (dimensions: $30 \mathrm{~m}$ x $320 \mu \mathrm{m}$ x 0.25

$199 \mu \mathrm{m}$; Agilent Technologies Inc, Santa Clara, USA), operating with helium as a carrier 200 gas. The oven was configured to $50^{\circ} \mathrm{C}$, and held for 1 minute, then ramped to $280{ }^{\circ} \mathrm{C}$ 
201 at a rate of $15^{\circ} \mathrm{C} \mathrm{min}-1$, and held for 8 minutes. The injector and the FID were held at $202300^{\circ} \mathrm{C}$.

\subsection{GC-MS analysis}

205

206 Plant and earthworm samples were all analysed using an Agilent 7890A Network GC system equipped with an HP5 capillary column (dimensions: $30 \mathrm{~m}$ x $250 \mu \mathrm{m}$ x 0.50 $\mu \mathrm{m}$; Agilent Technologies Inc), operating with helium as a carrier gas and coupled to

209 an Agilent 5975C mass spectrometer (MS) through a heated transfer line $\left(250^{\circ} \mathrm{C}\right)$.

210 The $\mathrm{GC}$ injector $\left(300^{\circ} \mathrm{C}\right)$ was operated in a pulsed splitless mode, $1 \mu \mathrm{l}$ aliquots were

211 injected using an autosampler, and the GC oven was programmed to hold $45^{\circ} \mathrm{C}$ for

$2122.25 \mathrm{~min}$ then raise the temperature by $40{ }^{\circ} \mathrm{C} / \mathrm{min}$ to $300{ }^{\circ} \mathrm{C}$, which was held for 6

213 minutes. The MS was operated in single ion monitoring (SIM) mode with electric

214 impact ionization.

\subsection{Statistical Analysis}

222 Chemical extractions and bioassays were compared using General Linear Regressions

223 in Genstat Release ver. 7 (Lawes Agricultural Trust, Rothamsted Experimental

\section{Station).}


3.0 Results

\subsection{PAH loss from spiked soil}

230 The loss of 2 and 3-ringed PAHs during the ageing period was more rapid than that of 231 the heavier 4-ringed PAHs as measured by the mechanical acetone hexane extraction 232 (Figure 1). All the naphthalene was depleted after 2 months and only pyrene and 233 fluoranthene remained in the soil in month 6 at both concentrations. The initial rate of 234 PAH loss was significantly greater for the $450 \mathrm{mg} \mathrm{kg}^{-1}$ concentration where $25 \%$ of 235 the original spike remained after 1 month compared to $50 \%$ in the $90 \mathrm{mg} \mathrm{kg}^{-1}$ 236 treatment $(\mathrm{p}<0.01)$. All the naphthalene was lost from both soils over the following 237 month and less than 5\% of the original spike of the other 2-3 ring PAHs remained 238 after month 3 . Less than $20 \%$ of the original amount of pyrene and fluoranthene 239 remained in the soil spiked with $90 \mathrm{mg} \mathrm{kg}^{-1}$ and less than $10 \%$ in the $450 \mathrm{mg} \mathrm{kg}^{-1}$ soil 240 after 6 months.

\subsection{Soil extractions - Total PAH}

244 The acetone hexane extraction extracted significantly more PAHs than any of the

245 chemical methods used to predict bioavailability at all five time points $(\mathrm{p}<0.01)$

246 (Figure 2). All the extractions were significantly different from each other over the 6 247 month period $(\mathrm{p}<0.05)$. Raising the contact time in the butanol extractions from 50s to 248120 s and 120 s to $12 \mathrm{~h}$ led to a significant increase in the total amount of PAHs 249 extracted $(\mathrm{p}<0.05)$. 


\subsection{Bioassay data}

253 There was no significant difference between the total amount of PAHs extracted from 254 the earthworms exposed to either soil after 0 and 1 months $(\mathrm{p}<0.01)$ (Figure 3$)$. After 255 month 1 there was a significant decline in PAH accumulation in the earthworms 256 exposed to the soil spiked with a total of $450 \mathrm{mg} \mathrm{kg}^{-1} \mathrm{PAH}$ at each successive time 257 point $(\mathrm{p}<0.01)$. There was no significant decline in earthworm accumulation in the 90 $258 \mathrm{mg} \mathrm{kg}^{-1}$ soil between month 2 and 3 but there was between months 1 and 2 and 259 months 3 and $6(\mathrm{p}<0.01)$.

261 The only significant decline in the total amount of PAH accumulated in the rye grass 262 roots was between months 0 and 1 in the soil spiked with $450 \mathrm{mg} \mathrm{kg}^{-1}$ PAH $(\mathrm{p}<0.01)$ 263 (Figure 4).

\subsection{Comparing chemical extractions with bioassay data}

267 General Linear Regression suggests that $12 \mathrm{~h}$ butanol extractions explain a larger 268 proportion of the variation in total PAH accumulated in earthworm tissue than any

269 other chemical extraction (Table 2). The $\mathrm{r}^{2}$ values are generally higher for the heavier 270 4-ringed PAHs (fluoranthene and pyrene) than for the 3-ringed PAHs (fluorene and 271 phenanthrene). $\mathrm{r}^{2}$ values for acenapthene are deceptively high as it virtually 272 disappears from the soil after month 2. Regression analysis was not possible for 273 naphthalene as it was not detected in earthworm tissue. 
Only cyclodextrin extractions explain a larger proportion of the variation in total PAH accumulated in plant tissue than the acetone hexane extraction (Table 3). Napthalene values are not included as it was only detecable in the soil in months 0 and 1 .

Comparisons between plants and earthworms should not be made using these values as plants were not sampled in the month 6 time point. Tenax extractions are not included in these tables as they were not performed throughout all time points either.

\subsection{Composition of accumulated and extracted PAHs}

For the month 0 soils there was a significantly larger percentage contribution of 4ringed PAHs in both the earthworm and plant accumulation bioassays relative to the chemical extractions ( $\mathrm{p}<0.01$ ), with the proportion of 4-ringed PAHs being less than $40 \%$ in all chemical extractions (Figure 5). The soils still contained a substantial amount of 2 and 3-ringed PAHs. There was also a significantly higher contribution of 2-ringed PAHs in the Tenax and cyclodextrin extractions than in any of the other extractions or bioassays $(\mathrm{p}<0.05)$.

On month 2 however, when the soils contained a substantially smaller amount of the 2 and 3-ringed PAHs, there was no significant difference between the PAH profiles of earthworms and butanol extractions in the soil spiked with $90 \mathrm{mg} \mathrm{kg}^{-1} \mathrm{PAH}(\mathrm{p}<0.05)$

(Figure 5). All other extractions had significantly different compositions than the earthworms $(\mathrm{p}<0.05)$, but they were substantially closer than in month 0 . The proportion of 4-ringed PAHs was higher than $60 \%$ for the acetone hexane and tenax extractions and higher than $90 \%$ in all others. There was no significant difference 
300 between the acetone hexane and plant extractions in the soil spiked with $450 \mathrm{mg} \mathrm{kg}^{-1}$

301 PAH $(p<0.05)$, there was a different between all others $(p<0.01)$, but again they were

302 substantially closer than in month 0.

\section{Discussion}

\subsection{PAH loss from spiked soil}

The low-molecular weight PAHs exhibited the highest loss rates. These PAHs are susceptible to abiotic processes like volatilization (Park et al., 1990). This together

310 with biodegradation is most likely responsible for the rapid loss of the 2-ringed PAHs

311 in the first month. For the remainder of the PAHs, biodegradation is likely to have

312 been the main loss process. There is a broad inverse relationship between the rate of 313 biodegradation and the number of rings in the PAH (Bossert and Bartha, 1986; Wild 314 and Jones, 1993) which is consistent with only the 4-ringed PAHs being detectable in 315 the 6 month old soils.

\subsection{Soil extractions}

The non exhaustive extractions only recovered a fraction of the PAHs extracted by the

321 acetone hexane extraction at all time points. This has been reported in other papers

322 where the fraction recovered by these non exhaustive extractions has been related to

323 the bioavailable fraction (Kelsey et al., 1997; Reid et al., 2000). However, the

324 different extraction techniques generally extracted different amounts of PAHs over 
325 the different time points. Differences between different chemical methods to predict

326 PAH bioavailability have also been found in a previous study, where a number of

327 chemical extractions were compared using PCA (Bergknut et al., 2007).

329 The fact that increasing the contact time of the butanol extractions significantly

330 increased the amounts of PAHs extracted has important implications when trying to

331 measure the bioavailable fraction as will be discussed in the following section.

332 Differences in extraction between the varying contact times were not as pronounced

333 in previous studies. Swindell and Reid (2006) found a vortexing time of 50s to be

334 appropriate as an approximation for the rapidly desorbing fraction and that increasing

335 it to 120 s as in Liste and Alexander (2002) made very little difference to the value

336 obtained.

4.3 Comparing chemical methods with the earthworm accumulation bioassay

340 The regressions show that the exhaustive extraction using acetone hexane does not 341 provide the best prediction of $\mathrm{PAH}$ accumulation in earthworms. Butanol extractions

342 had the better regression results. This is in line with earlier studies where mild

343 solvents were initially proposed as chemical methods to predict bioavailability

344 (Kelsey et al., 1997; Liste and Alexander, 2002), although much higher $\mathrm{r}^{2}$ values

345 (>0.90) have been found in other studies with butanol (Tang and Alexander, 1999).

346 The extraction with the longest contact time $12 \mathrm{~h}$, between the solvent and the soil,

347 showed the best correlations. Different contact times and mild solvents of varying

348 strength have been found to correlate differently with different bioassays and other

349 chemical methods to predict bioavailability (Kelsey et al., 1997; Tang and Alexander, 
1999; Liste and Alexander, 2002; Tang et al., 2002; Swindell and Reid, 2006;

351 Bergknut et al., 2007). A more rigorous defence of the extraction time chosen is 352 required.

354 Some studies have found butanol and other mild solvents to provide a poor indication 355 of earthworm bioavailability (White et al., 1997; Johnson et al., 2002). Jonhson et al. 356 (2002) suggest that butanol may be a good mimic of the passive uptake of chemicals 357 by organisms through their outer epidermis, but that it is less effective at predicting 358 the amount absorbed through the gut as here the soil structure and extraction 359 conditions are altered. Gut uptake could be higher than passive uptake through the 360 outer epidermis (Landrum, 1989), although this may not be the case with E. fetida as 361 it is an epigeic earthworm species and therefore consumes less soil than endogeic 362 earthworm species. This may be the reason for butanol having a relatively good 363 correlation in this study and strong correlations in the previously mentioned studies 364 where E. fetida was used as the test species, but not with the endogeic Aporrectodea 365 longa used in Johnson et al. (2002). It is therefore important to be aware of these 366 differences between species as results in investigations like this one are greatly 367 influenced by the choice of species.

368 Cyclodextrin extractions only slightly improved the prediction of PAH accumulation 369 relative to the acetone hexane extraction. There are some studies indicating that 370 cyclodextrin extractions of organic pesticides are a good indicator of earthworm 371 bioavailability (Hartnik et al., 2008), but most studies using PAHs indicate a poor 372 correlation with earthworm accumulation (Hickman and Reid, 2005; Bergknut et al., 373 2007). Reasons for this include that earthworms have complex accumulation 374 mechanisms, and that they can access compounds from both the aqueous and the solid 
375 phase (Gevao et al., 2001), suggesting the simple aqueous to hydrophobic sink model 376 provided by cyclodextrin or Tenax extractions may not account for the complexity of

377 the system. However, it is also important to consider that the lower sensitivity of these 378 methods due to the dilution stages and smaller masses of soil used in the extractions

379 relative to the butanol extractions could be another reason for their poorer

380 predictability.

382 The butanol and cyclodextrin extractions account for a larger percentage variance in 383 the amount of PAHs accumulated in the earthworm tissue than the acetone hexane 384 extractions, but there is still a large proportion of the variation in accumulated PAHs 385 unaccounted for by these extraction methods.

\subsection{Comparing chemical methods with the plant accumulation bioassay}

The chemical methods to predict bioavailability did not improve the description of the

390 variation in plant accumulation provided by the acetone hexane extraction. Other 391 attempts to compare plant accumulation with extractions using this solvent mixture 392 were not found, but a good correlation with hexane extractions was also observed by

393 Tao et al. (2006a). Here the amount of PAHs extracted by the water and hexane

394 fractions of a sequential extraction scheme using an accelerated solvent extraction

395 system was found to correlate well with accumulation in wheat roots. Tang and 396 Alexander (1999) found that a number of mild solvent extractions including butanol 397 correlated strongly $\left(r^{2}>0.89\right)$ with anthracene accumulation in wheat and barley roots, 398 but no direct indication of how an exhaustive extraction compared with this was 399 given. Tenax extractions have been shown to have potential to predict toxicity to 
plants as measured by the emergence of lettuce seedlings (Cofield et al., 2008), but no

401 studies have attempted to correlate either cyclodextrin or tenax extractions with plant accumulation to date. Further investigation is required in this field as non exhaustive methods to predict bioavailability should theoretically provide a better indication of

404 bioavailability to plants than exhaustive ones. Predicting the amount of PAHs that will 405 accumulate in plants is important from a human health perspective, as food ingestion 406 is the main source of human exposure to PAHs, with the major dietary contributions 407 being cereals and vegetables (Phillips, 1999).

409 It should be noted that in this study and in the one by Tao et al. (2006a), the plant 410 roots were only rinsed with water prior to analysis. It is therefore possible that the root 411 extractions included some PAHs sorbed to the root surface and therefore not strictly 412 accumulated within the roots (Tao et al., 2006b).

\subsection{Composition of accumulated and extracted PAHs}

The PAH profile of the earthworms and plants was different from the profile obtained by the soil extractions. Bergknut et al. (2007) observed a higher proportion of 5- and 6-ringed PAHs accumulated in earthworms than those extracted by a series of

419 chemical extractions using mild solvents and cyclodextrins amongst others. The 420 higher octanol-partitioning coefficient $\left(\mathrm{K}_{\mathrm{ow}}\right)$ of these heavier PAHs was given as the 421 reason for their increased accumulation. A strong negative correlation $\left(r^{2}=0.93\right)$ 422 between $\log \mathrm{K}_{\mathrm{ow}}$ and PAH elimination rate from earthworm tissue (Matscheko et al., 423 2002) and the fact that earthworms have been found to promote the degradation of the 424 more readily biodegradable PAHs (Ma et al., 1995) may have contributed to the 
increased accumulation of the heavier 4-ringed PAHs in the earthworms of this study.

426 Similar studies have also shown that PAHs with higher $\mathrm{K}_{\mathrm{ow}}$ accumulate more in plant roots than those of lower $\mathrm{K}_{\mathrm{ow}}$ (Gao and Ling, 2006), confirming earthworm and plant

428 accumulation are not only controlled by the bioavailable fraction of the contaminant

429 but also by contaminant characteristics. The greater proportion of heavier PAHs

430 accumulated by the plants and worms is highly significant from a risk assessment

431 point of view as these are generally the more toxic/carcinogenic/mutagenic

432 components. If a soil were to be extracted with a surrogate chemical assay the wrong

433 bioavailability/toxicity profile might be assumed. The same overall PAH

434 concentration as that of a bioassay may be obtained but hidden in that is the greater

435 proportion of the heavier and more toxic PAHs.

437 Tenax extractions have been found to provide good predictions of bioaccumulation of 438 PCBs and some organic pesticides in oligochaetes (You et al., 2006; Landrum et al., 439 2007). This was not the case for a number of PAHs including phenanthrene, and the 440 authors believed the most logical reason for this was that some PAHs are readily 441 biotransformed by some oligochaetes unlike most chlorinated compounds. Similarly 442 measuring the desorption of two pesticides into the aqueous phase using cyclodextrin 443 extractions has been found to predict pesticide uptake into earthworms, but not 444 pesticide bioaccumulation within the earthworm tissues (Hartnik et al., 2008).

445 Differences in bioaccumulation rates between compounds cannot necessarily be 446 explained by differences in the bioavailable fraction and are most likely due to 447 different metabolic fate in the organisms (Hartnik and Styrishave, 2008). Chemical 448 methods to predict bioavailability therefore cannot account for biological factors, like 449 elimination or biotransformation, which affect the accumulation of chemicals. This is 
probably one of the main reasons for the bioavailable fraction predicted by methods

451 such as cyclodextrin extractions to correlate strongly with microbial mineralisation

452 (Reid et al., 2000; Hickman and Reid, 2005; Allan et al., 2006; Papadopoulos et al.,

453 2007), but only correlate weakly with earthworm accumulation (Hickman and Reid,

454 2005). The fact that the compostion of the PAHs accumulated in plants and

455 earthworms also differed despite them being exposed to exactly the same soil

456 reiterates this point. PAHs will have different metabolic fates in different organisms

457 and it will be hard if not impossible to develop a chemical method that can mimic soil

458 biota to this level.

459

460 Some authors have used the Equilibrium Partitioning (EP) theory to account for the

461 different biota to sediment accumulation factors (BSAF) of different contaminants

462 (Krauss and Wilcke, 2001; Van der Wal et al., 2004b; Kreitinger et al., 2007). Van der

463 Wal et al. (2004b) for example used EP theory considering contaminant $\mathrm{K}_{\mathrm{ow}}$ and pore

464 water concentrations as measured by SPME fibres, to relate the bioavailable fraction

465 as measured by the SPME fibres to accumulation in earthworms. Measuring the

466 bioavailable fraction of a contaminant in this way and then combining it with EP

467 theory to obtain a prediction of earthworm accumulation may be a better way of

468 predicting earthworm and plant accumulation. However, Bergknut et al. (2007) found

469 poor correlations between PAH accumulation in earthworms and PAHs extracted by

470 SPME fibres using the method considering EP theory as proposed in Van der Wal et

471 al. (20004b). Using contaminant $\mathrm{K}_{\mathrm{ow}}$ on its own to predict accumulation may

472 therefore not be sufficient and other factors like organism specific uptake and

473 detoxification mechanisms may need to be included in the calculation. More research

474 into this issue is vital as being able to predict the uptake of PAHs by plants and 
475 earthworms has important implications both for human health and the environment

476 due to their accumulation potential up the food chain and their carcinogenicity.

\subsection{Conclusion}

479

480 Using accumulation bioassays to assess the capability of chemical methods to predict 481 the bioavailability of readily biotransformable or biodegradable PAHs is not a fair test 482 of their potential as bioavailability indicators. Even if they do provide a good estimate 483 of the bioavailable fraction other processes influence the accumulation of 484 contaminants in soil biota, including the physicochemical properties of the 485 contaminant and the characteristics of soil biota themselves. Modelling these 486 contaminant properties and soil biota uptake, biotransformation and elimination 487 mechanisms may be the best way of predicting the amount of contaminant 488 bioaccumulated in soil biota using the bioavailable fraction measured by chemical 489 methods.

\section{Acknowledgements:}

495 This study was funded by the Biotechnology and Biological Sciences Research 496 Council (BBSRC). 


\section{References:}

520 Alexander, M., 2000. Aging, bioavailability, and overestimation of risk from

521 environmental pollutants. Environmental Science \& Technology 34, 4259-4265.

522 Allan, I.J., Semple, K.T., Hare, R., Reid, B.J., 2006. Prediction of mono- and

523 polycyclic aromatic hydrocarbon degradation in spiked soils using cyclodextrin

524 extraction. Environmental Pollution 144, 562-571. 
525 Bergknut, M., Sehlin, E., Lundstedt, S., Andersson, P.L., Haglund, P., Tysklind, M., 526 2007. Comparison of techniques for estimating PAH bioavailability: Uptake in

527 Eisenia fetida, passive samplers and leaching using various solvents and additives.

528 Environmental Pollution 145, 154-160.

529 Bossert, I.D., Bartha, R., 1986. Structure-biodegradability relationships of polycyclic

530 aromatic-hydrocarbons in soil. Bulletin of Environmental Contamination and

531 Toxicology 37, 490-495.

532 Cofield, N., Banks, M.K., Schwab, A.P., 2008. Lability of polycyclic aromatic

533 hydrocarbons in the rhizosphere. Chemosphere 70, 1644-1652.

534 Contreras-Ramos, S.M., Alvarez-Bernal, D., Dendooven, L., 2008. Removal of

535 polycyclic aromatic hydrocarbons from soil amended with biosolid or vermicompost

536 in the presence of earthworms (Eisenia fetida). Soil Biology \& Biochemistry 40,

$537 \quad 1954-1959$.

538 Cornelissen, G., Rigterink, H., Ferdinandy, M.M.A., Van Noort, P.C.M., 1998.

539 Rapidly desorbing fractions of PAHs in contaminated sediments as a predictor of the

540 extent of bioremediation. Environmental Science \& Technology 32, 966-970.

541 Cuypers, C., Pancras, T., Grotenhuis, T., Rulkens, W., 2002. The estimation of PAH

542 bioavailability in contaminated sediments using hydroxypropyl-beta-cyclodextrin and

543 Triton X-100 extraction techniques. Chemosphere 46, 1235-1245.

544 Gao, Y.Z., Ling, W.T., 2006. Comparison for plant uptake of phenanthrene and

545 pyrene from soil and water. Biology and Fertility of Soils 42, 387-394.

546 Gevao, B., Mordaunt, C., Semple, K.T., Piearce, T.G., Jones, K.C., 2001.

547 Bioavailability of nonextractable (bound) pesticide residues to earthworms.

548 Environmental Science \& Technology 35, 501-507. 
549 Harmsen, J., 2007. Measuring bioavailability: From a scientific approach to standard 550 methods. Journal of Environmental Quality 36, 1420-1428.

551 Hartnik, T., Jensen, J., Hermens, J.L.M., 2008. Nonexhaustive $\beta$-Cyclodextrin

552 Extraction as a Chemical Tool To Estimate Bioavailability of Hydrophobic Pesticides

553 for Earthworms. Environmental Science \& Technology 42, 8419-8425.

554 Hartnik, T., Styrishave, B., 2008. Impact of Biotransformation and Bioavailability on 555 the Toxicity of the Insecticides $\alpha$-Cypermethrin and Chlorfenvinphos in Earthworm. 556 Journal of Agricultural and Food Chemistry 56, 11057-11064.

557 Hickman, Z.A., Reid, B.J., 2005. Towards a more appropriate water based extraction 558 for the assessment of organic contaminant availability. Environmental Pollution 138, $559299-306$.

560 Jager, T., Van der Wal, L., Fleuren, R., Barendregt, A., Hermens, J.L.M., 2005.

561 Bioaccumulation of organic chemicals in contaminated soils: Evaluation of bioassays 562 with earthworms. Environmental Science \& Technology 39, 293-298.

563 Jensen, J., Mesman, M., 2007. Ecological risk assessment of contaminated land:

564 Decision support for site specific investigations. RIVM report 7110701047.

565 Bilthoven, The Nethrelands.

566 Johnson, D.L., Jones, K.C., Langdon, C.J., Piearce, T.G., Semple, K.T., 2002.

567 Temporal changes in earthworm availability and extractability of polycyclic aromatic 568 hydrocarbons in soil. Soil Biology \& Biochemistry 34, 1363-1370.

569 Kelsey, J.W., Kottler, B.D., Alexander, M., 1997. Selective chemical extractants to 570 predict bioavailability of soil-aged organic chemicals. Environmental Science \& 571 Technology 31, 214-217. 
Krauss, M., Wilcke, W., 2001. Biomimetic extraction of PAHs and PCBs from soil with octadecyl-modified silica disks to predict their availability to earthworms.

574 Environmental Science \& Technology 35, 3931-3935.

575 Kreitinger, J.P., Quinones-Rivera, A., Neuhauser, E.F., Alexander, M., Hawthorne,

576 S.B., 2007. Supercritical carbon dioxide extraction as a predictor of polycyclic

577 aromatic hydrocarbon bioaccumulation and toxicity by earthworms in manufactured-

578 gas plant site soils. Environmental Toxicology And Chemistry 26, 1809-1817.

579 Landrum, P.F., 1989. Bioavailability and toxicokinetics of polycyclic aromatic-

580 hydrocarbons sorbed to sediments for the amphipod Pontoporeia hoyi. Environmental

$581 \quad$ Science \& Technology 23, 588-595.

582 Landrum, P.F., Robinson, S.D., Gossiaux, D.C., You, J., Lydy, M.J., Mitra, S., Ten

583 Hulscher, T.E.M., 2007. Predicting bioavailability of sediment-associated organic

584 contaminants for Diporeia spp. and Oligochaetes. Environmental Science \&

585 Technology 41, 6442-6447.

586 Liste, H.H., Alexander, M., 2002. Butanol extraction to predict bioavailability of

587 PAHs in soil. Chemosphere 46, 1011-1017.

588 Ma, W.C., Immerzeel, J., Bodt, J., 1995. Earthworm and food interactions on

589 bioaccumulation and disappearance in soil of polycyclic aromatic hydrocarbons:

590 Studies on phenanthrene and fluoranthene. Ecotoxicology and Environmental Safety

$59132,226-232$.

592 Matscheko, N., Lundstedt, S., Svensson, L., Harju, M., Tysklind, M., 2002.

593 Accumulation and elimination of 16 polycyclic aromatic compounds in the earthworm

594 (Eisenia fetida). Environmental Toxicology And Chemistry 21, 1724-1729. 

biodegradation in field contaminated soils using a cyclodextrin extraction technique.

597 Journal of Environmental Monitoring 9, 516-522.

598 Park, K.S., Sims, R.C., Dupont, R.R., Doucette, W.J., Matthews, J.E., 1990. Fate of

599 PAH compounds in 2 soil types - Influence of volatilization, abiotic loss and

600 biological-activity. Environmental Toxicology And Chemistry 9, 187-195.

601 Phillips, D.H., 1999. Polycyclic aromatic hydrocarbons in the diet. Mutation

602 Research-Genetic Toxicology and Environmental Mutagenesis 443, 139-147.

603 Reichenberg, F., Mayer, P., 2006. Two complementary sides of bioavailability:

604 Accessibility and chemical activity of organic contaminants in sediments and soils.

605 Environmental Toxicology And Chemistry 25, 1239-1245.

606 Reid, B.J., Northcott, G.L., Jones, K.C., Semple, K.T., 1998. Evaluation of spiking

607 procedures for the introduction of poorly water soluble contaminants into soil.

608 Environmental Science \& Technology 32, 3224-3227.

609 Reid, B.J., Stokes, J.D., Jones, K.C., Semple, K.T., 2000. Nonexhaustive

610 cyclodextrin-based extraction technique for the evaluation of PAH bioavailability.

611 Environmental Science \& Technology 34, 3174-3179.

612 Reid, B.J., Stokes, J.D., Jones, K.C., Semple, K.T., 2004. Influence of hydroxypropyl-

613 beta-cyclodextrin on the extraction and biodegradation of phenanthrene in soil.

614 Environmental Toxicology And Chemistry 23, 550-556.

615 Song, Y.F., Jing, X., Fleischmann, S., Wilke, B.M., 2002. Comparative study of

616 extraction methods for the determination of PAHs from contaminated soils and

617 sediments. Chemosphere 48, 993-1001.

618 Stokes, J.D., Wilkinson, A., Reid, B.J., Jones, K.C., Semple, K.T., 2005. Prediction of 619 polycyclic aromatic hydrocarbon biodegradation in contaminated soils using an 
aqueous hydroxypropyl-beta-cyclodextrin extraction technique. Environmental

621 Toxicology And Chemistry 24, 1325-1330.

622 Stroo, H.F., Jensen, R., Loehr, R.C., Nakles, D.V., Fairbrother, A., Liban, C.B., 2000.

623 Environmentally acceptable endpoints for PAHs at a manufactured gas plant site.

624 Environmental Science \& Technology 34, 3831-3836.

625 Swindell, A.L., Reid, B.J., 2006. Comparison of selected non-exhaustive extraction

626 techniques to assess PAH availability in dissimilar soils. Chemosphere 62, 1126-

6271134.

628 Tang, J.X., Alexander, M., 1999. Mild extractability and bioavailability of polycyclic 629 aromatic hydrocarbons in soil. Environmental Toxicology And Chemistry 18, 2711 6302714.

631 Tang, J.X., Liste, H.H., Alexander, M., 2002. Chemical assays of availability to

632 earthworms of polycyclic aromatic hydrocarbons in soil. Chemosphere 48, 35-42.

633 Tao, S., Jiao, X.C., Chen, S.H., Liu, W.X., Coveney, R.M., Zhu, L.Z., Luo, Y.M., 634 2006b. Accumulation and distribution of polycyclic aromatic hydrocarbons in rice 635 (Oryza sativa). Environmental Pollution 140, 406-415.

636 Tao, S., Xu, F.L., Liu, W.X., Cui, Y.H., Coveney, R.M., 2006a. A chemical extraction 637 method for mimicking bioavailability of polycyclic aromatic hydrocarbons to wheat 638 grown in soils containing various amounts of organic matter. Environmental Science $639 \&$ Technology 40, 2219-2224.

640 Ten Hulscher, T.E.M., Postma, J., Den Besten, P.J., Stroomberg, G.J., Belfroid, A., 641 Wegener, J.W., Faber, J.H., Van der Pol, J.J.C., Hendriks, A.J., Van Noort, P.C.M., 642 2003. Tenax extraction mimics benthic and terrestrial bioavailability of organic 643 compounds. Environmental Toxicology And Chemistry 22, 2258-2265. 
644 Van der Wal, L., Jager, T., Fleuren, R., Barendregt, A., Sinnige, T.L., Van Gestel,

645 C.A.M., Hermens, J.L.M., 2004b. Solid-phase microextraction to predict

646 bioavailability and accumulation of organic micropollutants in terrestrial organisms

647 after exposure to a field-contaminated soil. Environmental Science \& Technology 38,

$648 \quad 4842-4848$.

649 Van der Wal, L., Van Gestel, C.A.M., Hermens, J.L.M., 2004a. Solid phase

650 microextraction as a tool to predict internal concentrations of soil contaminants in

651 terrestrial organisms after exposure to a laboratory standard soil. Chemosphere 54,

$652561-568$.

653 White, J.C., Kelsey, J.W., Hatzinger, P.B., Alexander, M., 1997. Factors affecting

654 sequestration and bioavailability of phenanthrene in soils. Environmental Toxicology

655 And Chemistry 16, 2040-2045.

656 Wild, S.R., Jones, K.C., 1993. Biological and abiotic losses of polynuclear aromatic-

657 hydrocarbons (PAHs) from soils freshly amended with sewage-sludge. Environmental

658 Toxicology And Chemistry 12, 5-12.

659 You, J., Landrum, P.F., Lydy, M.J., 2006. Comparison of chemical approaches for

660 assessing bioavailability of sediment-associated contaminants. Environmental Science

$661 \&$ Technology 40, 6348-6353.

662

663

664

665 Table 1. Chemical and physical properties of the Kettering loam soil.

\begin{tabular}{|l|l|l|l|l|}
\hline $\mathrm{pH}$ & Organic Matter (\%) & Sand (\%) & Silt (\%) & Clay (\%) \\
\hline 7.1 & 5.0 & 66.9 & 21.74 & 11.76 \\
\hline
\end{tabular}

666 
687 Table 2. Results of General Linear Regressions between the total and individual

688 amount of PAHs extracted by the acetone hexane shake (AH), the cyclodextrin

689 extraction (CD), the 50s butanol mix (BM50s), the 120s butanol mix (BM120s) and 690 the $12 \mathrm{~h}$ butanol shake (BS12h) relative to the amounts accumulated in the earthworm $691 \quad$ E. fetida. 


\begin{tabular}{|c|c|c|c|c|c|}
\hline & $\mathrm{AH}$ & $\mathrm{CD}$ & BM50s & BM120s & BS12h \\
\hline $\begin{array}{l}\text { Acenapthene } \\
\mathrm{r}^{2} \\
\mathrm{p}\end{array}$ & $\begin{array}{l}0.81 \\
<0.01\end{array}$ & $\begin{array}{l}0.78 \\
<0.01\end{array}$ & $\begin{array}{l}0.80 \\
<0.01\end{array}$ & $\begin{array}{l}0.82 \\
<0.01\end{array}$ & $\begin{array}{l}0.86 \\
<0.01\end{array}$ \\
\hline $\begin{array}{l}\text { Fluorene } \\
\mathrm{r}^{2} \\
\mathrm{p}\end{array}$ & $\begin{array}{l}0.03 \\
0.30 \\
\end{array}$ & $0^{a}$ & $0^{a}$ & $\begin{array}{l}0.02 \\
0.31 \\
\end{array}$ & $\begin{array}{l}0.06 \\
0.24 \\
\end{array}$ \\
\hline $\begin{array}{l}\text { Phenanthrene } \\
\mathrm{r}^{2} \\
\mathrm{p}\end{array}$ & $0^{\mathrm{a}}$ & $0^{\mathrm{a}}$ & $0^{\mathrm{a}}$ & $\begin{array}{l}0.01 \\
0.34 \\
\end{array}$ & $\begin{array}{l}0.20 \\
0.11 \\
\end{array}$ \\
\hline $\begin{array}{l}\text { Fluoranthene } \\
\mathrm{r}^{2} \\
\mathrm{p}\end{array}$ & $\begin{array}{l}0.55 \\
0.01\end{array}$ & $\begin{array}{l}0.40 \\
0.03\end{array}$ & $\begin{array}{l}0.63 \\
<0.01\end{array}$ & $\begin{array}{l}0.59 \\
0.01\end{array}$ & $\begin{array}{l}0.47 \\
0.02\end{array}$ \\
\hline $\begin{array}{l}\text { Pyrene } \\
\mathrm{r}^{2} \\
\mathrm{p}\end{array}$ & $\begin{array}{l}0.55 \\
0.01 \\
\end{array}$ & $\begin{array}{l}0.48 \\
0.02 \\
\end{array}$ & $\begin{array}{l}0.76 \\
<0.01\end{array}$ & $\begin{array}{l}0.62 \\
<0.01\end{array}$ & $\begin{array}{l}0.47 \\
0.02\end{array}$ \\
\hline $\begin{array}{l}\text { Total PAH } \\
\mathrm{r}^{2} \\
\mathrm{p}\end{array}$ & $\begin{array}{l}0.48 \\
0.02\end{array}$ & $\begin{array}{l}0.51 \\
0.03\end{array}$ & $\begin{array}{l}0.54 \\
0.01\end{array}$ & $\begin{array}{l}0.60 \\
0.01\end{array}$ & $\begin{array}{l}0.64 \\
<0.01\end{array}$ \\
\hline
\end{tabular}

${ }^{\mathrm{a}}$ Residual variance exceeds variance of response variate

693

694

695

696

697

698

699

700

701

702

703 Table 3. Results of General Linear Regressions between the total and individual

704 amount of PAHs extracted by the acetone hexane shake (AH), the cyclodextrin

705 extraction (CD), the 50s butanol mix (BM50s), the 120s butanol mix (BM120s) and

706 the $12 \mathrm{~h}$ butanol shake (BS12h) relative to the amounts accumulated in the rye grass

707 (L. multiflorum) roots. 


\begin{tabular}{|l|l|l|l|l|l|}
\hline & AH & CD & BM50s & BM120s & BS12h \\
\hline Acenapthene & & & & & \\
$\mathrm{r}^{2}$ & 0.84 & 0.85 & 0.76 & 0.75 & 0.94 \\
$\mathrm{p}$ & 0.01 & 0.01 & 0.01 & 0.02 & $<0.01$ \\
\hline Fluorene & & & & & \\
$\mathrm{r}^{2}$ & 0.64 & 0.68 & 0.68 & 0.66 & 0.62 \\
$\mathrm{p}$ & 0.04 & 0.03 & 0.03 & 0.03 & 0.04 \\
\hline Phenanthrene & & & & & \\
$\mathrm{r}^{2}$ & 0.07 & 0.11 & 0.09 & 0.06 & \\
$\mathrm{p}$ & 0.31 & 0.27 & 0.29 & 0.32 & $0^{\mathrm{a}}$ \\
\hline Fluoranthene & & & & & \\
$\mathrm{r}^{2}$ & 0.80 & 0.84 & 0.70 & 0.36 & \\
$\mathrm{p}$ & 0.01 & 0.01 & 0.03 & 0.12 & $0^{\mathrm{a}}$ \\
\hline Pyrene & & & & & \\
$\mathrm{r}^{2}$ & 0.73 & 0.78 & 0.57 & 0.19 & \\
$\mathrm{p}$ & 0.02 & 0.01 & 0.05 & 0.21 & $0^{\mathrm{a}}$ \\
\hline Total PAH & & & & & \\
$\mathrm{r}^{2}$ & 0.95 & 0.97 & 0.93 & 0.86 & 0.82 \\
$\mathrm{p}$ & $<0.01$ & $<0.01$ & $<0.01$ & 0.01 & 0.01 \\
\hline $\mathrm{a}$ & & & & \\
\hline
\end{tabular}

